\title{
Serological response to $\mathrm{mRNA}$ and inactivated COVID-19 vaccine in healthcare workers in Hong Kong: preliminary results
}

published on 24 Jun 2021 at www.hkmj.org.
Hong Kong Med J 2021;27:312-3

https://doi.org/10.12809/hkmj219605

To the Editor-Healthcare workers (HCWs) in Hong Kong are among the priority groups to receive coronavirus disease 2019 (COVID-19) vaccination. We recruited HCWs who enrolled for COVID-19 vaccination from 22 February to 30 April 2021 for serial measurement of their anti-spike immunoglobulin M (IgM)/immunoglobulin G (IgG)/ total antibody and surrogate neutralising antibody using Abbott SARS-CoV-2 IgM/IgG II Quant assay; Roche Elecsys ${ }^{\circledR}$ Anti-SARS-CoV-2 S, and GenScript cPass SARS-CoV-2 Surrogate Virus Neutralization Test Kit. The key exclusion criteria were history of polymerase chain reaction-confirmed COVID-19 or positive test for severe acute respiratory syndrome coronavirus 2-specific IgG or IgM in the serum. The

TABLE I. Characteristics of the study cohort*

\begin{tabular}{|lccc|}
\hline Assumptions & $\begin{array}{c}\text { CoronaVac } \\
(\mathbf{n}=212)\end{array}$ & $\begin{array}{c}\text { BNT162b2 } \\
(\mathbf{n}=234)\end{array}$ & P value $^{\dagger}$ \\
\hline Age, y & $49.11 \pm 9.87$ & $44.06 \pm 11.03$ & $<0.0001$ \\
\hline Sex & & & 0.0136 \\
\hline Male & $83(39.15 \%)$ & $119(50.85 \%)$ & \\
\hline Female & $129(60.85 \%)$ & $115(49.15 \%)$ & \\
\hline Medical co-morbidities & & & \\
\hline None & $145(68.40 \%)$ & $182(77.78 \%)$ & 0.0318 \\
\hline Diabetes mellitus & $10(4.72 \%)$ & $10(4.27 \%)$ & 0.8237 \\
\hline Hypertension & $24(11.32 \%)$ & $16(6.84 \%)$ & 0.1345 \\
\hline Hyperlipidaemia & $26(12.26 \%)$ & $21(8.97 \%)$ & 0.2821 \\
\hline Cardiovascular disease & $3(1.42 \%)$ & $1(0.43 \%)$ & 0.3504 \\
\hline Asthma & $2(0.94 \%)$ & $7(2.99 \%)$ & 0.1801 \\
\hline Chronic renal disease & $1(0.47 \%)$ & $1(0.43 \%)$ & 1 \\
\hline Chronic liver disease or cirrhosis & $6(2.83 \%)$ & $5(2.14 \%)$ & 0.7633 \\
\hline History of malignancy ${ }^{\ddagger}$ & $10(4.72 \%)$ & $1(0.43 \%)$ & 0.0041 \\
\hline Systemic lupus erythematosus & $1(0.47 \%)$ & 0 & 0.4753 \\
\hline Other autoimmune disease & $8(3.77 \%)^{\S}$ & $1(0.43 \%)^{\Perp}$ & 0.0156 \\
\hline Medication & & & \\
\hline Steroid & 1 & 0 & 0.4753 \\
\hline Non-Steroid Immunosuppressant & 2 & 0 & 0.2254 \\
\hline
\end{tabular}

Data are shown as mean \pm standard deviation or No. (\%), unless otherwise specified No. of positive test results was tested using Fisher's exact test. Means were tested using $t$ test. A P value of $<0.05$ was considered statistically significant

All without chemotherapy or radiotherapy in the past 6 months

One case of immunoglobulin A nephropathy, two cases of non-specific arthritis receiving hydroxychloroquine, one case of psoriatic arthritis receiving methotrexate and upadacitinib, one case of ankylosing spondylitis receiving ixekizumab, one case of rheumatoid arthritis receiving hydroxychloroquine, and two cases of ocular myasthenia gravis

Ulcerative colitis receiving treatment with mesalazine clinical trial protocol was approved by the Research Ethics Committee of Hong Kong Sanatorium and Hospital Medical Group (Ref: RC-2021-07).

Of the $457 \mathrm{HCWs}$ recruited, 220 (48.1\%) selected an inactivated vaccine (CoronaVac; Sinovac Life Sciences, Beijing, China) and 237 (51.9\%) selected an mRNA vaccine (BNT162b2/Comirnaty; Fosun-BioNTech Pharma), based on their personal preference. The CoronaVac arm was older (mean age $=49.11$ vs 44.06 years; $\mathrm{P}<0.0001$ ) and had a higher prevalence of having at least one medical comorbidity (31.6\% vs $22.22 \% ; \mathrm{P}=0.0318$ ) [Table 1 ].

At the time of writing, 210 participants have received two doses of CoronaVac and 92 have received two doses of BNT162b2. After dose 1, more BNT162b2 recipients had positive anti-spike IgG than did CoronaVac recipients $(99.1 \%$ vs $64.7 \%$; $\mathrm{P}<0.0001)$. However, the majority developed antispike IgG after dose 2 with no significant difference between the two arms (100\% vs 99\%; $\mathrm{P}=1)$ [Table 2]. Of 289 samples taken after receiving dose 2, only two were negative for anti-spike IgG. These two non-responders were both immunocompromised, one with psoriatic arthritis receiving methotrexate treatment, and the other with chronic lymphocytic leukaemia. The IgG and total antibody levels induced by BNT162b2 were higher than those induced by CoronaVac after dose $1(\mathrm{P}<0.0001)$ and after dose $2(\mathrm{P}<0.0001)$ [Fig]. After dose 2, more BNT162b2 recipients had positive surrogate neutralising antibody (100\% vs 94\%; $\mathrm{P}<0.0194)$.

Both CoronaVac and BNT162b2 are immunogenic in these HCWs. Our findings underscore the importance of maintaining social distancing and other infection control measures until 4 weeks after completing the two-dose regimen. Although most vaccine recipients developed antibodies after the second dose, the level of antibody or neutralising activity required to confer protection against future infection is currently not well defined. More research is needed for a better understanding of serology after vaccination. Data collection is ongoing and new findings will be published when available.

\section{Author contributions}

JST Zee drafted the letter. All authors contributed to the concept or design of the study, acquisition of the data, analysis or interpretation of the data, and critical revision of the letter for important intellectual content. All authors had full access to the data, contributed to the study, approved the final version 
TABLE 2. Antibody levels after vaccination with CoronaVac or BNTI62b2*

\begin{tabular}{|c|c|c|c|c|c|c|}
\hline & \multicolumn{2}{|c|}{ CoronaVac } & \multicolumn{2}{|c|}{ BNT162b2 } & \multicolumn{2}{|c|}{$\begin{array}{c}\text { P value }^{\dagger} \\
\text { (CoronaVac vs BNT162b2) }^{\text {(C) }}\end{array}$} \\
\hline & $\begin{array}{l}\text { After dose } 1 \\
\text { ( } \geq 26 \text { days })\end{array}$ & $\begin{array}{l}\text { After dose } 2 \\
\text { ( } \geq 28 \text { days) }\end{array}$ & $\begin{array}{l}\text { After dose } 1 \\
(\geq 19 \text { days })\end{array}$ & $\begin{array}{l}\text { After dose } 2 \\
\text { ( } \geq 28 \text { days) }\end{array}$ & After dose 1 & After dose 2 \\
\hline $\begin{array}{l}\text { No. of serum samples available } \\
\text { for analysis }{ }^{\ddagger}\end{array}$ & 207 & 198 & 226 & 91 & & \\
\hline \multicolumn{7}{|l|}{ Roche Elecsys $₫$ total antibody } \\
\hline Antibody positive results & $157(75.8 \%)$ & 197 (99.5\%) & 224 (99.1\%) & $91(100 \%)$ & $<0.0001$ & 1 \\
\hline $\begin{array}{l}\text { Antibody level, U/mL, mean } \\
(95 \% \mathrm{Cl})\end{array}$ & $9.6(5.5-13.8)$ & $141.7(129.7-153.6)$ & $104.2(93.3-115.3)$ & $244.1(237.2-251.1)$ & $<0.0001$ & $<0.0001$ \\
\hline \multicolumn{7}{|l|}{ Abbott SARS-CoV-2 IgG } \\
\hline Antibody positive results & $134(64.7 \%)$ & $196(99.0 \%)$ & $224(99.1 \%)$ & $91(100 \%)$ & $<0.0001$ & 1 \\
\hline $\begin{array}{l}\text { Antibody level, } \mathrm{AU} / \mathrm{mL} \text {, mean } \\
(95 \% \mathrm{Cl})\end{array}$ & $157.6(105.8-209.5)$ & $\begin{array}{c}1005.2 \\
(850.3-1160.0)\end{array}$ & $\begin{array}{c}1618.0 \\
(1430.0-1806.0)\end{array}$ & $\begin{array}{c}11572.6 \\
(9928.8-13216.4)\end{array}$ & $<0.0001$ & $<0.0001$ \\
\hline \multicolumn{7}{|l|}{$\begin{array}{l}\text { GenScript cPass surrogate } \\
\text { neutralising antibody }\end{array}$} \\
\hline Antibody positive results & 40 (19.3\%) & $187(94.4 \%)$ & $213(94.2 \%)$ & $91(100 \%)$ & $<0.0001$ & $<0.0194$ \\
\hline $\begin{array}{l}\text { Antibody level, \% signal } \\
\text { inhibition, mean }(95 \% \mathrm{Cl})\end{array}$ & $15.59(12.8-18.3)$ & $66.7(63.9-69.6)$ & $66.0(63.4-68.6)$ & $94.5(92.6-96.4)$ & $<0.0001$ & $<0.0001$ \\
\hline \multicolumn{7}{|c|}{$\begin{array}{l}\text { Abbreviations: } 95 \% \mathrm{Cl}=95 \% \text { confidence interval; IgG = immunoglobulin G; SARS-CoV-2 = severe acute respiratory syndrome coronavirus } 2 \\
\text { Data are shown } \mathrm{No} \text {. (\%), unless otherwise specified } \\
\text { No. of positive was tested using Fisher's exact test. Means were tested using } t \text { test. A P value of }<0.05 \text { was considered statistically significant } \\
\neq \text { Samples that were not collected according to protocol were excluded from analysis: sera were collected } \geq 19 \text { days after dose I of BNTI } 62 \mathrm{~b} 2, \geq 26 \text { days } \\
\text { after dose I of CoronaVac and } \geq 28 \text { days after dose } 2 \text { of either vaccine }\end{array}$} \\
\hline
\end{tabular}
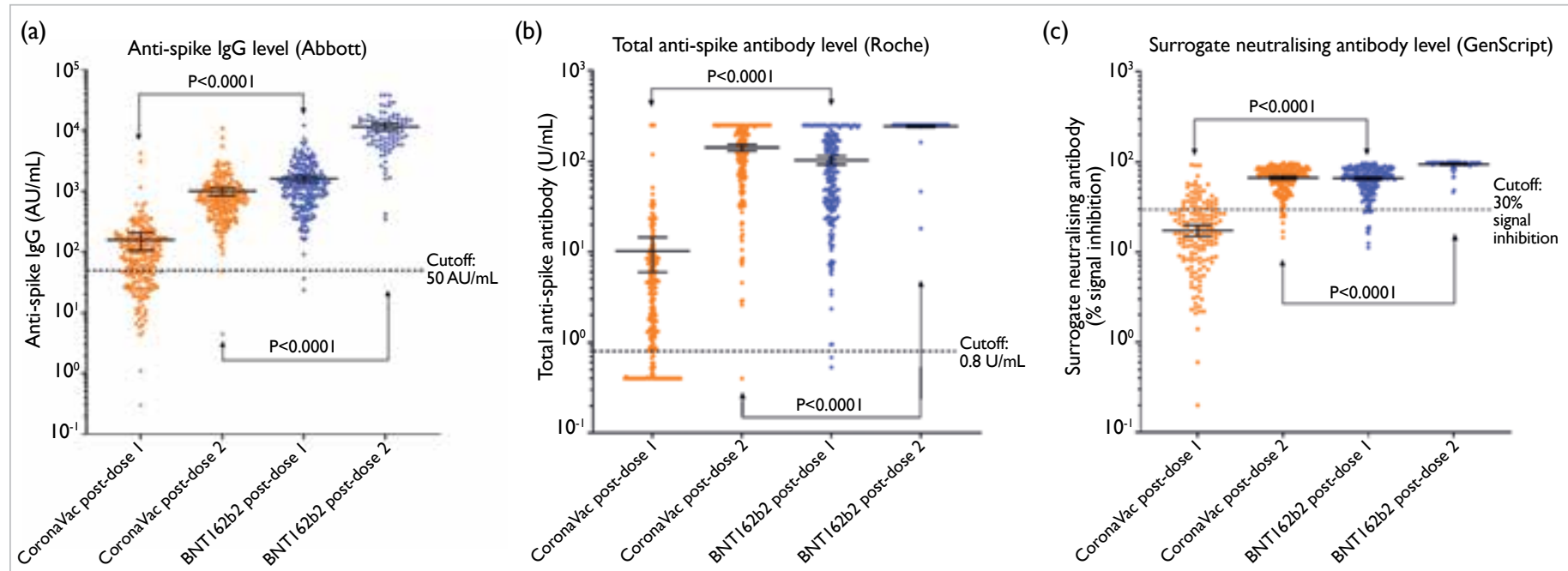

FIG. (a) Anti-spike immunoglobulin G (lgG) level, (b) total anti-spike antibody level, (c) surrogate neutralising antibody level after dose I and 2 of CoronaVac and BNT162b2. Each dot represents the antibody level of a participant after dose I or dose 2 of CoronaVac or BNTI62b2. Sera were collected $\geq 19$ days after dose I of BNTI62b2, $\geq 26$ days after dose I of CoronaVac, and $\geq 28$ days after dose 2 of either vaccine. Long horizontal bars indicate mean values, error bars indicate $95 \%$ confidence intervals, and dotted lines indicate cut-off values for positive test results. Means were compared using $t$ test

for publication, and take responsibility for its accuracy and integrity.

\section{Conflicts of interest}

All authors have disclosed no conflicts of interest.

1,2 Jonpaul ST Zee *, FRCPath, FHKAM (Medicine)

${ }^{1}$ Kristi TW Lai, MMedSc (HKU)

${ }^{1}$ Matthew KS Ho, MMedSc (HKU)

${ }^{1}$ Alex CP Leung, MMedSc (HKU)

${ }^{2}$ Queenie WL Chan, BScN, FHKAN (Medicine-Infection Control)
${ }^{1}$ Edmond SK Ma, MD (HK), FRCPath

${ }^{3}$ KH Lee, MMedSc (HKU), FHKAM (Community Medicine)

${ }^{3}$ CC Lau, MB, BS, FHKAM (Emergency Medicine)

1,2,3 Raymond WH Yung, MB, BS, FHKCPath

1 Department of Pathology, Hong Kong Sanatorium and Hospital, Hong Kong

2 Infection Control Team, Hong Kong Sanatorium and Hospital, Hong Kong

${ }^{3}$ Hospital Administration, Hong Kong Sanatorium and Hospital, Hong Kong

*Corresponding author: jonpaul.st.zee@hksh.com 